\title{
Angiosarcoma arising in a neurofibromatosis-1 patient as a de novo malignancy?
}

\author{
Xavier Dubernard*1, Bach-Ngam Pham ${ }^{2}$, Michel Pluot ${ }^{3}$, Yohan Renard ${ }^{4}$, Marc Labrousse ${ }^{1,5}$ \\ ${ }^{1}$ Department of Otorhinolaryngology, Faculty of Medicine and University Hospital, Universite de Reims Champagne-Ardenne, \\ Reims, France \\ ${ }^{2}$ Department of Immunology, Faculty of Medicine and University Hospital, Universite de Reims Champagne-Ardenne, Reims, \\ France \\ ${ }^{3}$ Department of Biopathology, Faculty of Medicine and University Hospital, Universite de Reims Champagne-Ardenne, Reims, \\ France \\ ${ }^{4}$ Department of Digestive Surgery, Faculty of Medicine and University Hospital, Universite de Reims Champagne-Ardenne, \\ Reims, France \\ ${ }^{5}$ Department of Anatomy, Faculty of Medicine, Universite de Reims Champagne-Ardenne, Reims, France
}

Received: May 4, 2019

DOI: $10.5430 /$ crcp.v6n1p13
Accepted: July 1, 2019

Online Published: July 25, 2019

URL: https://doi.org/10.5430/crcp.v6n1p13

\begin{abstract}
Background. Neurofibromatosis-1 (NF-1) is the most common genetic disease belonging to the group of neural tissue cell growth disorders, known to be complicated by malignant peripheral nerve sheath tumors or MPNST. On the contrary, angiosarcoma is rarely associated with NF-1. Only few cases reported angiosarcoma arising as a sarcomatous transformation within a preexisting MPNST.

Methods and results. We report here the remarkable case of a 35-year-old NF-1 woman, with a history of excised MPNST 8 years before a new hospitalization for the development of multi localized angiosarcoma, whose discovery is related to an oropharyngeal involvement, with a dramatic presentation. Review of the literature and differences from previous reports are discussed.

Conclusion. Our case report supports the hypothesis of an angiosarcoma developing as a malignant proliferation apparently not arising from contiguous neurofibroma or MPNST lesions, but representing a second de novo malignancy.
\end{abstract}

Key Words: Angiosarcoma, Neurofibromatosis, von Recklinghausen's disease, Malignant peripheral nerve sheath tumors, Sarcomatous malignancy

\section{INTRODUCTION}

Neurofibromatosis-1 (NF-1), formerly termed von Recklinghausen's disease, is the most common genetic disease belonging to the group of neural tissue cell growth disorders, comprising two distinct subtypes, NF-1 and NF-2. NF-1 has a birth incidence of about 1 in 2500, and a prevalence of 1 in $4000 .^{[1,2]}$ The clinical manifestations are hyperpigmented macular skin lesions (café-au-lait spots), multiple cutaneous neurofibromas (nerve sheath tumours along the peripheral nerves), optic gliomas, skin-fold freckling, Lisch nodules (harmartomas of iris), and specific skeletal alterations. The clinical expression is highly variable in affected NF-1 indi-

\footnotetext{
*Correspondence: Xavier Dubernard; Email: xdubernard@chu-reims.fr; Address: Department of Otorhinolaryngology, Faculty of Medicine and University Hospital, Hopital Robert Debre, av du General KOENIG, 51092 REIMS cedex, France. 
viduals, ranging from mild lesions to severe complications, even within families. This autosomal dominant disease has been associated with molecular abnormalities identified in the tumor suppressor NF1 gene. ${ }^{[3,4]}$ This gene is known to encode the neurofibromin protein, a negative regulator of the ras signal transduction pathway, involved in the control of cell growth. ${ }^{[5,6]}$

Neurofibromas are benign peripheral nerve sheath tumors comprising Schwann cells, fibroblast, perineurial cells, mast cells and axons in an extracellular matrix. Although neurofibromas usually run indolent course, a malignant transformation may occur as classic complication, arising in about $2 \%-3 \%$ of NF-1 patients with a lifetime risk of $8 \%-13 \% .{ }^{[7,8]}$ Malignant peripheral nerve sheath tumors or MPNST (term replacing malignant schwannoma, neurofibrosarcoma, and neurogenic sarcoma) are aggressive sarcoma tumors comprising $5 \%$ to $10 \%$ of all soft tissue sarcomas, one half to two thirds arising from neurofibromas. ${ }^{[9]}$ On the contrary, angiosarcoma, a malignancy of vascular origin comprising about $2 \%$ of soft tissue sarcomas, is rarely associated with NF-1. Only a few cases have been reported in the literature. ${ }^{[10-17]}$ We report here the case of a 35-year-old woman known with a NF-1 disease, who developed a metastatic angiosarcoma, without MPNST components on histologic tumor examination.

\section{Case Presentation}

A 35-year-old woman was admitted in emergency for an epistaxis and an oral bleeding. She had a family history (mother and daughter with NF-1) and medical history of NF1, with multiple neurofibromas resected. Eight years earlier, the patient developed a right popliteal tumor. The complete surgical resection of the tumor $(75 \mathrm{~mm} \times 5 \mathrm{~mm})$, expanding from the external popliteal sciatic nerve, led to the diagnosis of MPNST grade II. The patient was postoperatively treated with adjunctive chimiotherapy.

On admission, the physical examination showed multiple café-au-lait colored spots and cutaneous neurofibromas. Intraoral examination found multiple exophytic haemorrhagic buccal masses of both buccal vestibules attached to the gingivae (see Figure 1), and to rhinopharynx. Slight bleeding was noticed. The results of laboratory studies revealed an acute anemia $(\mathrm{Hb}=70 \mathrm{~g} / \mathrm{L})$. The patient received a transfusion of 4 red blood cell (RBC) units. A cervical computed tomography (CT) was performed. The early post-contrast images showed a voluminous heterogeneous rhinopharyngeal obstructive mass (see Figure 2), estimated at $35 \mathrm{~mm} \times 30 \mathrm{~mm} \times 30$ $\mathrm{mm}$, with active bleeding. Surgery of the three buccal and the rhinopharyngeal masses was then decided (see Figure 3). Tumors were completely resected. Seven days after surgery, just before discharge, the clinical evolution was marked by severe abdominal pains associated with a massive blood loss $(\mathrm{Hb}=50 \mathrm{~g} / \mathrm{L})$ requiring the transfusion of $7 \mathrm{RBC}$ units and 4 units of fresh frozen plasma.

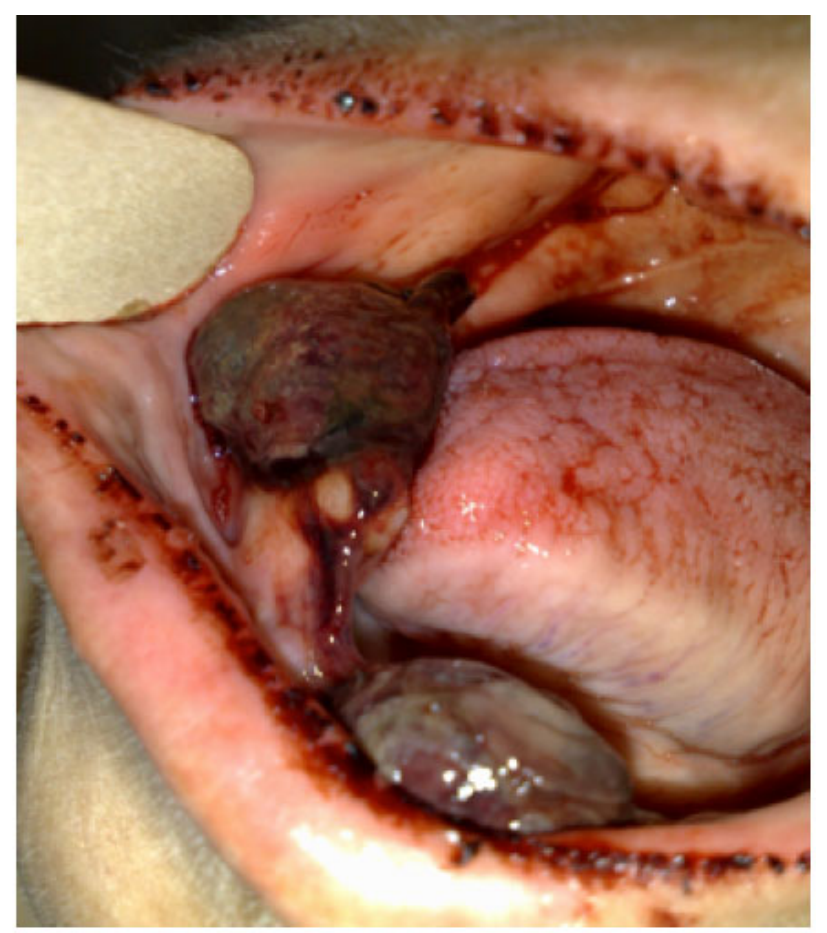

Figure 1. Haemorragic gingival masses

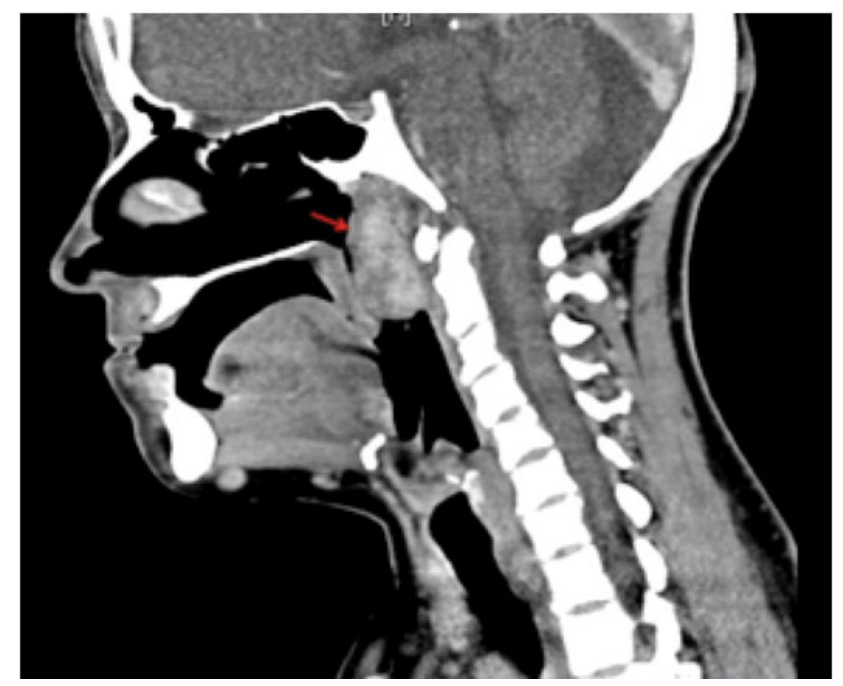

Figure 2. Cervical computed tomography scan showing a voluminous heterogeneous rhinopharyngeal obstructive mass

The pelvic CT scan showed a very important hemoperitoneum (see Figure 4). About 5L of hemorrhagic fluid was surgically drained in emergency. The laparoscopy revealed the presence of a left ovarian mass ruptured tubal with 
peritoneal extension. A left salpingo-oophorectomy was therefore performed. Thoracic CT and cerebral magnetic resonance imaging scan (see Figure 5) revealed multiple pleural lesions associated with hemorrhagic chest mass syndrome, and multiple hemorrhagic and necrotic brain lesions with peripheral edema. During the post-operative period, an early local recurrence of gingival and nasopharyngeal lesions appeared within one week after resection. The patient experienced blood loss resulting in a $2 \mathrm{RBC}$ unit transfusion. Since further surgical therapy of cerebral and lung lesions was impossible, a chemotherapy was programmed associated to supportive measures. Unfortunately, the patient died 10 days after the last surgical operation.

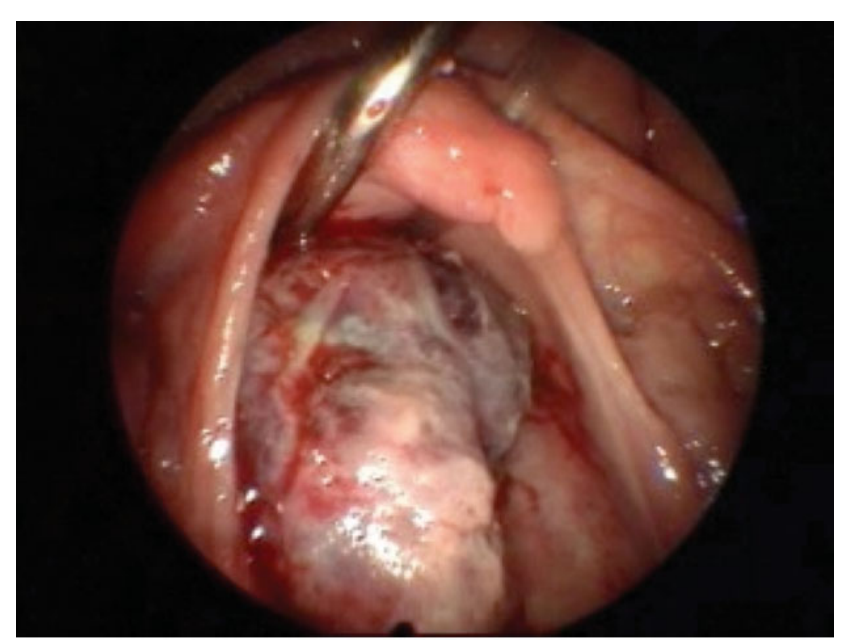

Figure 3. Posterior cavumscopy per-operative view showing voluminous heterogeneous rhinopharyngeal obstructive mass

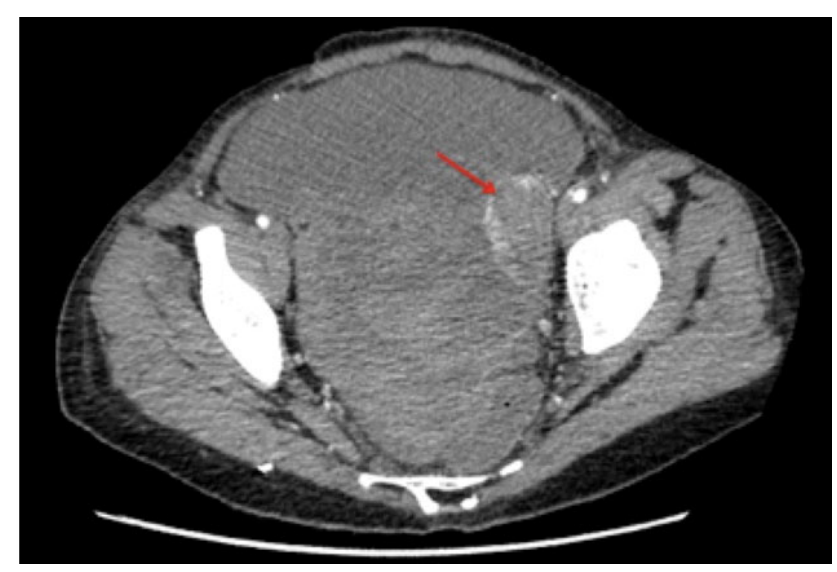

Figure 4. Pelvic computed tomography scan with voluminous hemoperitoneum. Suspicion of a left ovarian metastasis (red arrow)

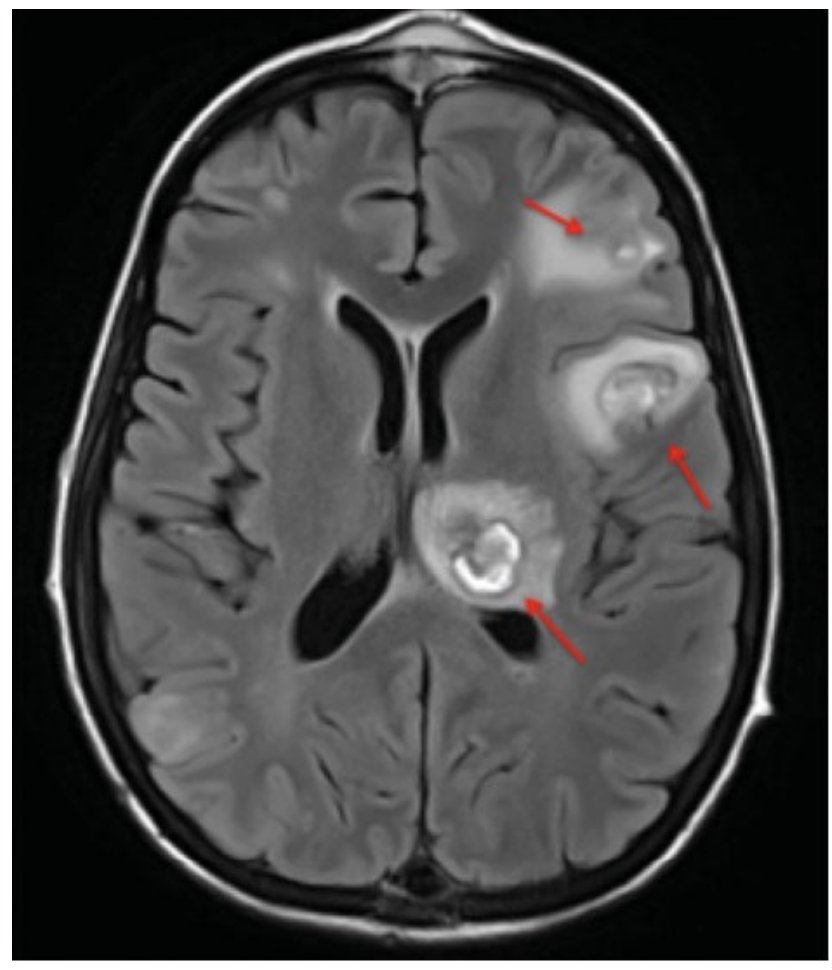

Figure 5. Cerebral computed tomography scan revealing hemorrhagic and necrotic left brain lesions with peripheral oedema (red arrow)

The right popliteal tumor, completely excised 8 years before the present case report, expanded the external popliteal sciatic nerve of origin. The well circumscribed lesion exhibited a neurofibroma aspect with sarcoma degeneration areas. Microscopic examination of sarcoma degeneration areas showed irregular areas of high cellularity composed of spindle-shaped cells with atypical irregular nuclei and thin cytoplasm. The tumor cells were arranged in dimly interlacing fascicles. There was no sign of vascular spread. Necrosis was present in more than $50 \%$ of the observed tumor sections. About $30 \%$ of tumor cells were reactive for S-100 protein. Pathological diagnosis was MPNST grade II.

Regarding the initial event reported in this case, histologic sections of the initial excision specimens of both nasopharynx and buccal vestibules demonstrated an ulcerated tumor surface, coated with fibrin and polymorphonuclear leukocytes. It consisted of multiple more or less anastomosing splits, delimited by very atypical endothelial cells with a high nucleo-cytoplasmic ratio. The nuclei were hyperchromatic and monstrous. Many mitotic figures were observed. Some cavities contained erythrocytes (see Figure 6). A polymorphic inflammatory infiltrate composed of neutrophils and lymphocytes was found in the stroma. An immunohistochemical study was performed. It showed a very strong positive staining of tumor cells when using anti-CD31, anti- 
CD34 antibodies (see Figure 7). Ki67 proliferation index was estimated at $50 \%$. No staining was observed when using an anti-HHV8 antibody. Pathological diagnosis was angiosarcoma grade III. The tumor did not arise within a nerve or neurofibroma. No cytologic alterations related to neurofibroma or MPNST was observed. Immunostaining with anti-S100 antibodies and anti-Glial Fibrillary Acidic Protein (GFAP) antibodies was negative.

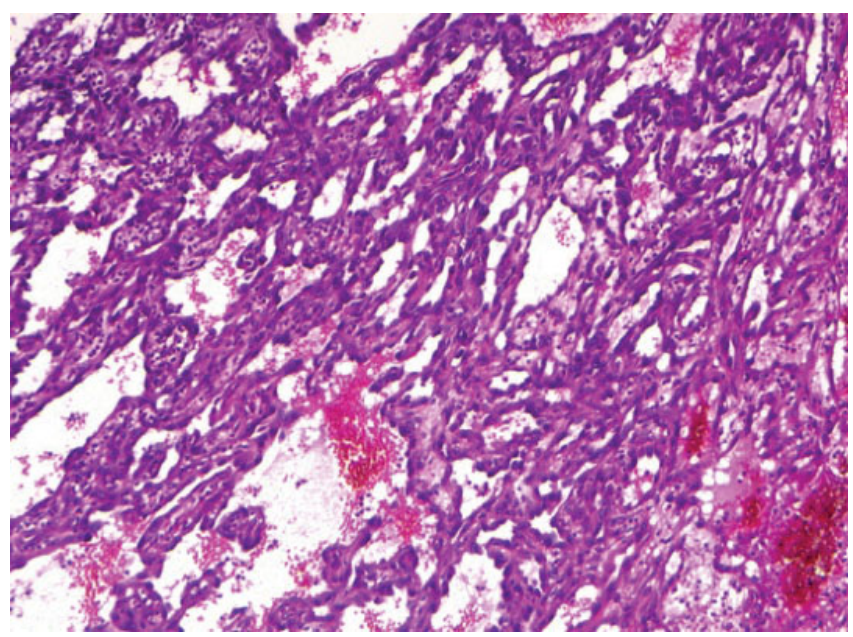

Figure 6. Rhinopharynx. Irregularly shaped tumoral blood vessels containing erythrocytes(HE;x200).

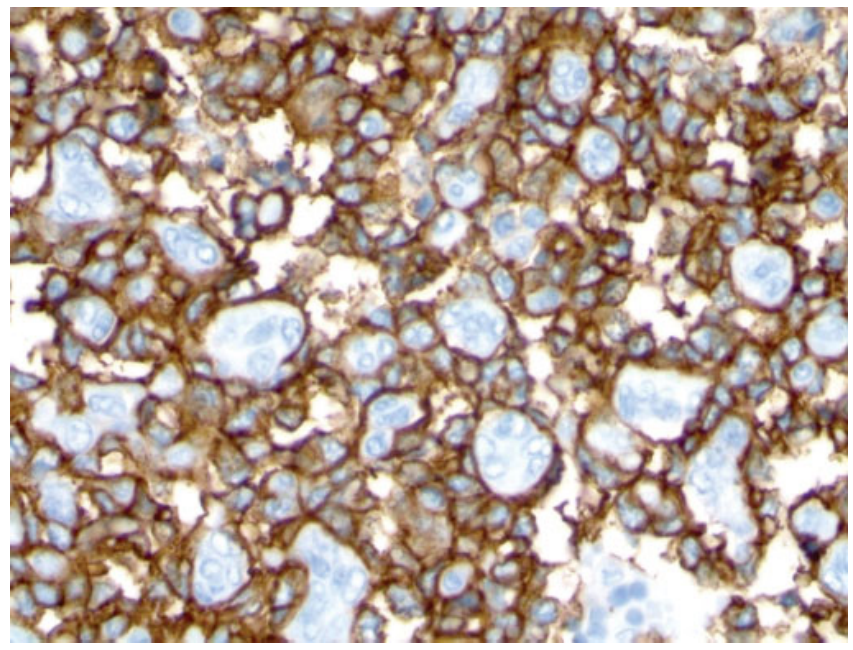

Figure 7. Rhinopharynx. The immunohistochemistry study using an CD 34 antibody shows that CD34 is expressed by the tumoral proliferation(x300).

The examination of the salpingo-oophorectomy piece related to the second clinical event also demonstrated angiosarcomatous tumoral structures infiltrating the ovaria parenchyma massively (see Figure 8). The tumor invaded the mesosalpinx and the contiguous peritoneum. The proliferation was more compact than in the rhinopharynx with an equally high K167 proliferation index (see Figure 9). Unfortunately, no post mortem examination was performed. A review of the right popliteal tumor specimens confirmed the histologic diagnosis of MPNST grade II, without angiosarcoma.

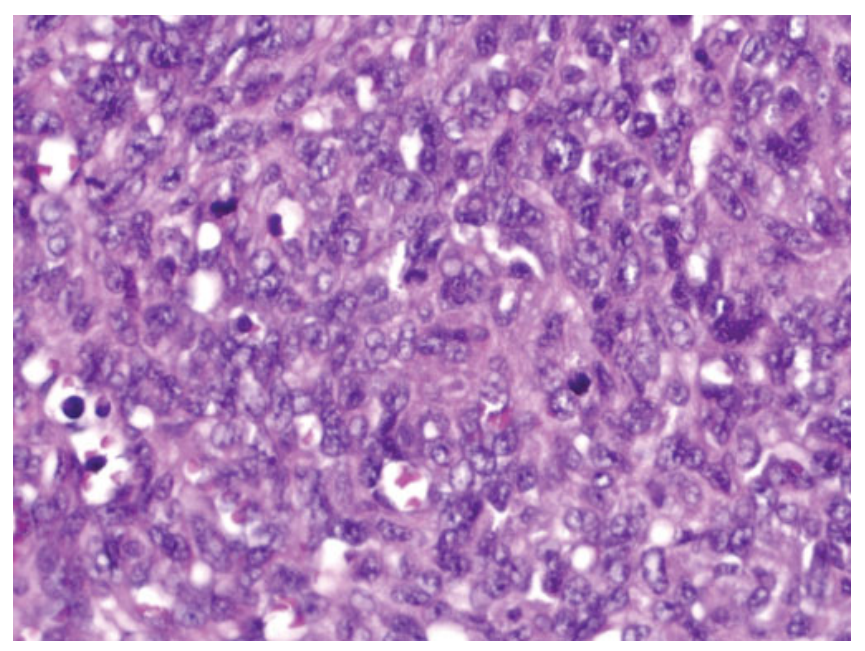

Figure 8. Left ovary: cellular compact proliferation with tiny vascular lumina; presence of mitoses (HE; 300$)$.

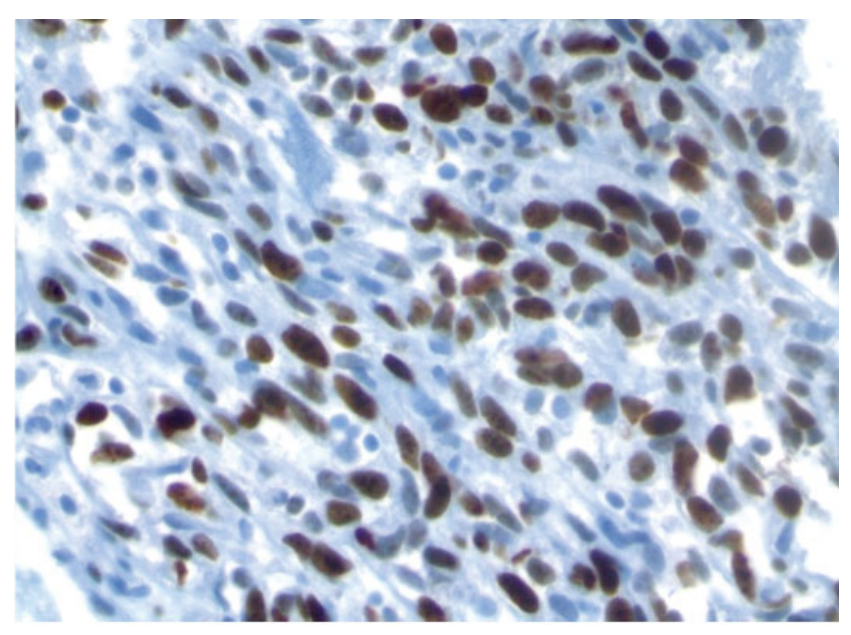

Figure 9. Left ovary: The immunohistochemistry study shows a strong Ki 67 positivity (x350).

\section{Discussion}

NF-1 patients are predisposed to benign and malignant tumor development. Increased incidence of both MPNST and epithelial tumors are well documented. On the contrary, angiosarcoma is a rare complication of NF-1. Few cases have been reported (see Table 1). We report here the case of a 35-year-old NF-1 woman, with a history of excised MPNST 8 years before a new hospitalization for the development of 
multi localized angiosarcoma. This case report was remarkable in that angiosarcoma developed in a female patient, as the second malignancy with a dramatic presentation. Actually, the death was caused by multiple hemorrhagic locations of an angiosarcomatous proliferation (oral, nasopharyngeal, ovarian and also probably pulmonary and cerebral locations). The aggressive nature of the angiosarcoma was demonstrated by the early local recurrence of gingival and nasopharyngeal lesions (within one week).

Table 1. Table with all cases of angiosarcoma with MPNST described in the literature

\begin{tabular}{lllll}
\hline First Author & $\begin{array}{l}\text { Number } \\
\text { of cases }\end{array}$ & year & Age & $\begin{array}{l}\text { Reference } \\
\text { PMID }\end{array}$ \\
\hline Ito T & 1 & 1966 & 66 & 16995966 \\
Macaulay RA & 1 & 1978 & 18 & 96219 \\
Lederman SM & 1 & 1987 & 21 & 3096807 \\
Brown RW & 1 & 1992 & 20 & 1515988 \\
Trassard M & 1 & 1996 & 65 & 8898847 \\
Mentzel t & 2 & 1999 & {$[63-73]$} & 10460655 \\
Rückert RI & 1 & 2000 & 50 & 11013374 \\
McMenamin ME & 17 & 2001 & {$[16-76]$} & 11145248 \\
Shundo Y & 1 & 2002 & 68 & 12233103 \\
Lee FY & 1 & 2007 & 73 & 17574948 \\
Elli M & 1 & 2007 & 13 & 18338507 \\
Li C & 1 & 2012 & 68 & 22726071 \\
Koethe Y & 1 & 2013 & 18 & 23922330 \\
Ogawa T & 1 & 2014 & $/$ & 23720355 \\
Sakai Y & 1 & 2014 & 33 & 24599662 \\
Vrushali Mahajan & 1 & 2015 & 41 & 25371276 \\
Marija Milković Periša & 1 & 2017 & 12.5 & 29138703 \\
Winter AC & 1 & 2017 & $/$ & 28548697 \\
Mrowczynski OD & 1 & 2018 & 14 & 29616298 \\
Lazaridou M & 1 & 2019 & 62 & 30617438 \\
\hline
\end{tabular}

In NF-1 patients, whether angiosarcoma develops as a malignant transformation or occurs simultaneously with peripheral nerve tumors is still a matter of debate. Our case report supports the first hypothesis of an angiosarcoma developing as a malignant proliferation apparently not arising from contiguous neurofibroma or MPNST lesions. Microscopic examination of the buccal, rhinopharyngeal tumors and of the abdominal tumor showed pure angiosarcoma, but neither histological evidence of neurofibroma nor MPNST transformation. However, it may not be totally ruled out that neurofibroma or MPNST occurred in the non-sampled lesions in a patient with a history of excised MPNST eight years before. Our data are also in accordance with that of Millstein et al., reporting the case of scrotal skin angiosarcoma in a 61year-old man with NF-1, whose histologic analysis affirmed

\section{REFERENCES}

[1] Ferner RE, Huson SM, Thomas N, et al. Guidelines for the diagnosis and management of individuals with neurofibromatosis 1 . J Med Genet 2007;44:81-8. PMid:17105749. https ://doi .org/10.113 6/jmg. 2006.045906 that there were "no neurofibromatous changes" in or about the genital lesion. ${ }^{[18]}$ The second hypothesis is that angiosarcoma occurs simultaneously with MPNST, representing a pluripotent differentiation of nerve sheath neuroectoderm as proposed by Ducatman, ${ }^{[19]}$ or representing a "metaplasia" within an existing MPNST as proposed by Macaulay ${ }^{[20]}$ MPNSTs represent a heterogeneous group of malignancies derived from Schwann cells or pluripotent cells of the neural crest. $^{[21,22]}$ Epithelioid or heterologous differentiation can be found in $15 \%$ of MPNSTs, including rhabdomyoblasts as the most common on (Triton tumor), smooth muscle, bone, cartilage, and neuroendocrine components. MPNST with focal divergent differentiation to angiosarcoma is the rarest event. In 1978, Macaulay ${ }^{[20]}$ described, in an 18-year-old NF-1 patient, a MPNST of the radial nerve presenting a gradual transition from malignant schwannoma pattern to an angiosarcoma pattern. The patient died of cerebral hemorrhage. Metastases in brain and lung showed pure angiosarcoma whereas metastases in adrenal glands showed both malignant schwannoma and angiosarcoma. ${ }^{[20]}$ Later, Lederman ${ }^{[11]}$ reported the malignant transformation of one liver neurofibroma from multiple ones, showing irregular transition areas with an angiosarcoma component. ${ }^{[11]}$ In 1992, Brown et al. ${ }^{[10]}$ published the case of a NF-1 patient with multiple neurofibromas, presenting an angiosarcoma transformation of a large nerve trunk, with unequivocal transitional areas between angiosarcoma and malignant MPNST ${ }^{[10]}$ Lastly, angiosarcoma and MPNST may be distinct histologic patterns within the same neoplasm. ${ }^{[1]}$

Occurrence of angiosarcoma is not coincidental with NF-1. In our report, angiosarcoma may represent a second de novo malignancy. Consequently, NF-1 patients should be assessed periodically to rule out any malignant change. Currently, developed navigation technology and multimodality image fusion may facilitate biopsies for diagnosis purposes. ${ }^{[23]} \mathrm{In}$ addition, NF-1 is associated with diverse genetic modifications, as deletion, insertion or mutation in the NF-1 gene. Yet, outcome of malignant phenotypes may require additional genetic events. ${ }^{[24-26]}$ In this way, pathogenetic mechanisms involved in NF-1 patients with angiosarcoma should be investigated.

\section{CONFlicts of InTEREST Disclosure}

The authors declare that they have no competing interest.
[2] Ferner RE. Neurofibromatosis 1. Eur J Hum Genet EJHG. 2007; 15: 131-8. PMid:16957683. https://doi.org/10.1038/sj.e jhg. 5201676

[3] Viskochil D, Buchberg AM, Xu G, et al. Deletions and a translocation interrupt a cloned gene at the neurofibromatosis type 1 locus. Cell. 
1990; 62: 187-92. https://doi.org/10.1016/0092-8674(90 ) $90252-A$

[4] Wallace MR, Marchuk DA, Andersen LB, et al. Type 1 neurofibromatosis gene: identification of a large transcript disrupted in three NF1 patients. Science. 1990; 249: 181-6. PMid:2134734. https://doi.org/10.1126/science. 2134734

[5] Daston MM, Scrable H, Nordlund M, et al. The protein product of the neurofibromatosis type 1 gene is expressed at highest abundance in neurons, Schwann cells, and oligodendrocytes. Neuron. 1992; 8: 415-28. https: //doi .org/10.1016/0896-6273(92)90270-N

[6] Bollag G, Clapp DW, Shih S, et al. Loss of NF1 results in activation of the Ras signaling pathway and leads to aberrant growth in haematopoietic cells. Nat Genet. 1996; 12: 144-8. PMid:8563751. https ://doi.org/10.1038/ng0296-144

[7] Woodruff JM. Pathology of tumors of the peripheral nerve sheath in type 1 neurofibromatosis. Am J Med Genet 1999; 89: 23-30. https://doi.org/10.1002/(SICI) 1096-8628(19 990326) $89: 1<23:$ : AID-AJMG6>3.0.CO;2-\#

[8] Evans DGR, Baser ME, McGaughran J, et al. Malignant peripheral nerve sheath tumours in neurofibromatosis 1 . J Med Genet. 2002; 39: 311-4. PMid:12011145. https://doi .org/10.1136/jmg.39.5 .311

[9] Tucker T, Wolkenstein P, Revuz J, et al. Association between benign and malignant peripheral nerve sheath tumors in NF1. Neurology. 2005; 65: 205-11. PMid:16043787. https ://doi.org/10.1212/ 01.wnl.0000168830.79997.13

[10] Brown RW, Tornos C, Evans HL. Angiosarcoma arising from malignant schwannoma in a patient with neurofibromatosis. Cancer. 1992; 70: 1141-4. https://doi.org/10.1002/1097-0142(19 920901)70:5<1141: :AID-CNCR2820700519>3.0.CO;2-Q

[11] Lederman SM, Martin EC, Laffey KT, et al. Hepatic neurofibromatosis, malignant schwannoma, and angiosarcoma in von Recklinghausen's disease. Gastroenterology. 1987; 92: 234-9. https : //doi.org/10.1016/0016-5085(87)90866-3

[12] Riccardi VM, Wheeler TM, Pickard LR, et al. The pathophysiology of neurofibromatosis. II. Angiosarcoma as a complication. Cancer Genet Cytogenet. 1984; 12: 275-80. https://doi.org/10.101 6/0165-4608(84)90040-2

[13] Mentzel T, Katenkamp D. Intraneural angiosarcoma and angiosarcoma arising in benign and malignant peripheral nerve sheath tumours: clinicopathological and immunohistochemical analysis of four cases. Histopathology. 1999; 35: 114-20. https ://doi.org/ 10.1046/j.1365-2559.1999.00714.x

[14] Png MA, Teh HS, Poh WT. Case report: angiosarcoma in a patient with von Recklinghausen's disease. Clin Radiol. 1996; 51: 521-3. https ://doi.org/10.1016/S0009-9260 (96)80197-8

[15] Marija Milković Periša, Tihana Džombeta, Jasminka Stepan Giljević and Božo Krušlin. Malignant Peripheral Nerve Sheath Tumor of the Inguinum and Angiosarcoma of the Scalp in a Child with Neurofibro- matosis Type 1 Case Reports in Pathology Volume 2017, Article ID 7542825, 4 pages. PMid:29138703. https ://doi.org/10.1155/ $2017 / 7542825$

[16] Winters AC, Black JO, Carrye R. Cost Metastatic angiosarcoma arising in malignant peripheral nerve sheath tumor in a young patient with neurofibromatosis type 1. Pediatr Blood Cancer. 2017 Dec; 64(12). PMid:28548697. https ://doi .org/10.1002/pbc. 26643

[17] Sakai Y, Hirose T, Tomono A, et al. Angiosarcoma arising in schwannoma of cerebellopontine angle and later associating with meningioma in a patient with neurofibromatosis type 2. Brain Tumor Pathol 2014 Oct; 31(4): 293-8. PMid:24599662. https ://doi .org/10.1 007/s10014-014-0180-6

[18] Millstein DI, Tang CK, Campbell EW. Angiosarcoma developing in a patient with Neurofibromatosis (von Recklinghausen's disease). Cancer. 1981; 47: 950-4. https ://doi .org/10.1002/1097-014 2(19810301) $47: 5<950:$ : AID-CNCR2820470522>3 . 0.CO; 2- J

[19] Ducatman BS, Scheithauer BW. Malignant peripheral nerve sheath tumors with divergent differentiation. Cancer. 1984; 54: 1049-57. https ://doi.org/10.1002/1097-0142(198409 15) $54: 6<1049::$ AID-CNCR2820540620>3.0.CO;2-1

[20] Macaulay RA. Neurofibrosarcoma of the radial nerve in von Recklinghausen's disease with metastatic angiosarcoma. J Neurol Neurosurg Psychiatry. 1978; 41: 474-8. PMid:96219. https://doi.org/10 $.1136 /$ jnnp.41.5.474

[21] Guo A, Liu A, Wei L, et al. Malignant peripheral nerve sheath tumors: differentiation patterns and immunohistochemical features - a mini-review and our new findings. J Cancer. 2012; 3: 303-9. PMid:22773934. https://doi.org/10.7150/jca.4179

[22] Danid N, Hiroko O, Otmar D. The 2007 WHO Classification of Tumours-pathology and genetics of tumors of the nervous system. WHO, 2007. vol. 4 ed, 2007. PMid:23922330. https://doi.org/ $10.1002 / \mathrm{pbc} .24668$

[23] Koethe Y, Widemann BC, Hajjar F, et al. PET-guided biopsy with needle navigation facilitates diagnosis of angiosarcoma in neurofibromatosis type 1. Pediatr Blood Cancer. 2013; 60: E166-169. PMid:23922330. https : //doi.org/10.1002/pbc. 24668

[24] Nielsen GP, Stemmer-Rachamimov AO, Ino Y, et al. Malignant transformation of neurofibromas in neurofibromatosis 1 is associated with CDKN2A/p16 inactivation. Am J Pathol. 1999; 155: 1879-84. https : //doi .org/10.1016/S0002-9440(10)65507-1

[25] Kourea HP, Cordon-Cardo C, Dudas M, et al. Expression of p27(kip) and other cell cycle regulators in malignant peripheral nerve sheath tumors and neurofibromas: the emerging role of p27(kip) in malignant transformation of neurofibromas. Am J Pathol. 1999; 155: 1885-91. https://doi.org/10.1016/S0002-9440(10)65508-3

[26] Menon AG, Anderson KM, Riccardi VM, et al. Chromosome 17p deletions and p53 gene mutations associated with the formation of malignant neurofibrosarcomas in von Recklinghausen neurofibromatosis. Proc Natl Acad Sci U S A. 1990; 87: 5435-9. PMid:2142531. https://doi.org/10.1073/pnas.87.14.5435 